Çukurova Üniversitesi Mühendislik Mimarlık Fakültesi Dergisi, 33(4), ss. 97-110, Aralık 2018

Çukurova University Journal of the Faculty of Engineering and Architecture, 33(4), pp. 97-110, December 2018

\title{
Genetik Algoritma ile Öznitelik Seçimi Kullanılarak Yapım Yönetiminde Çalışan Liderlik Algısının Tahmini
}

\author{
Abdullah Emre KELEŞ ${ }^{1}$, Mümine KAYA KELEŞ*2 \\ ${ }^{1}$ Adana Bilim ve Teknoloji Üniversitesi, Mühendislik Fakültesi, İnşaat Mühendisliği Bölümü, \\ Adana \\ ${ }^{2}$ Adana Bilim ve Teknoloji Üniversitesi, Mühendislik Fakültesi, Bilgisayar Mühendisliği Bölümü, \\ Adana
}

Geliş tarihi: $02.04 .2018 \quad$ Kabul tarihi: 25.12 .2018

Öz

Hızla büyüyen ticari teknolojiler için bilimsel bir temel hazırlayan ve birçok uygulama alanına sahip olan yapay zekânın son zamanlarda inşaat projelerinde de kullanımı dikkat çekmeye başlamıştır. Bu çalışmada, inşaat projelerinin temelini oluşturan yapım yönetimi konusunda yapay zekâ sistemlerinin kullanım alanları incelenmiş olup, Türkiye özelinde literatür taraması gerçekleştirildikten sonra yapım yönetiminde önemli bir yeri olan çalışan liderlik algısının sınıflandırılmasında taranan bu literatürlerde yapay zeka yöntemlerinden başarılı olan genetik algoritma ile öznitelik seçiminin önemi araştırılmıştır. Çalışma sonucunda, çalışan liderlik algısının tahmin edilebilmesi amacıyla hazırlanmış olan veri setinde öznitelik seçimi yapıldıktan sonra Naive Bayes, Destek Vektör Makineleri (SMO), Çok Katmanlı Algılayıcı (MLP), Radyal Tabanlı Fonksiyon Ağları (RBF Network), Karar Tablosu (Decision Table) ve J48 sınıflayıcıları çalıștırılmıș, J48 sınıflayıcısı ile doğruluk oranının ham veri setine göre artarak \%78,43 olduğu gözlenmiştir.

Anahtar Kelimeler: İnşaat projeleri, Öznitelik seçimi, Yapay zekâ, Yapı bilişimi, Yapım yönetimi

\section{Prediction of Employee Leadership Perception in Construction Management Using Feature Selection with Genetic Algorithm}

\begin{abstract}
Artificial intelligence, which is a scientific basis for rapidly growing commercial technologies and has many application areas, has recently begun to draw attention to its use in construction projects. In this study, the use of artificial intelligence systems in construction management, which is the basis of construction projects, was examined, and after the literature review was performed in Turkey in particular, the importance of feature selection with genetic algorithm that were successful in the artificial intelligence methods in these reviewed literatures was investigated in classification of employee leadership perception, which has an important place in construction management. As a result of the study, after the feature selection was done in the data set prepared to predict the employee leadership perception, Naive Bayes, SMO, MLP, RBF Network, Decision Table and J48 classifiers were run, and it was observed that the accuracy rate with J48 classifier was increased to $78.43 \%$ with respect to the raw data set.
\end{abstract}

Keywords: Construction projects, Feature selection, Artificial intelligence, Construction informatics, Construction management

*Sorumlu yazar (Corresponding author): Mümine KAYA KELEŞ, mkaya@adanabtu.edu.tr 


\section{GíRiș}

Kullanım amacı, insan hayatını kolaylaştırmak, kullanıldığ 1 sektörlerdeki kaliteyi ve verimliliği arttırmak, özellikle tehlikeli işlerde iş kazaları riskini robot vb. ekipmanları kullanarak en aza indirgemek, eğitimde strateji geliştirme ve problem çözme (muhakeme) yeteneği kazandırmak olan Yapay Zekâ, bilginin kullanımı üzerine kurulan bir teknolojidir.

Bilgisayar biliminin bir dalı olan Yapay Zekâ (YZ), Bulanık Mantık, Doğa Esinlemeli Algoritmalar, Doğal Dil İşleme, Genetik Algoritmalar, Konuşmayı Tanıma, Makina Görme Yeteneği, Makine Öğrenmesi, Örüntü Tanıma, Robotik, Ses Tanıma, Uzman Sistemler, Yapay Sinir Ağları (YSA) konularıyla yakından ilgilenmekte ve bu alanlarda uygulama imkânı bulmaktadir.

Son yıllarda yapılan çalışmalar; kullanılan YZ Tabanlı Sistemlerin üretimi arttırdığı, kaliteyi yükselttiği ve maliyeti azalttığını göstermektedir [1]. Planlamada, lojistikte, fabrika planında, vb. verimliliği arttırdığı gözlendikçe YZ'nin diğer bilim dalları üzerinde etkisinin artmakta olması pek şaşırtıcı bir sonuç olmamaktadır.

YZ'nin bir alt dalı olan Makine öğrenmesi, çeşitli görevlerin öğrenilmesi, mantıksal ve ikili çıkarımlar yoluyla otomatik hesaplama yöntemlerini kapsayan bir süreç olarak düşünülmektedir [2]. Makine öğrenmesi ile önceki deneyimlere veya örnek veri setlerine dayanan bir işlem optimize edilebilmekte, siniflandirılabilmekte veya tahmin edilebilmektedir. Ancak veri setinin başarısını etkileyen birçok öznitelik bulunmaktadır. Bunların bazılarının ölçülebilir faktörler olmasından dolayı, nu özniteliklerin, veri setinin başarısını hangi düzeyde etkilediğinin bilinmesi gerekmektedir. $\mathrm{Bu}$ sebeple veri setindeki tüm öznitelikler yerine, veri setini daha belirgin özellikleriyle yansitabilecek, onu daha iyi temsil edebilecek daha az sayıda öznitelik belirlenebilirse sinıflandırma yöntemlerinin tahmin başarım oranlarının artabileceği düşünülmektedir [3].
Öznitelik seçimi, sınıflandırıcının doğruluğunu arttırmak ve ilgili hesaplama maliyetlerini en aza indirgemek, muhtemelen ilgisiz öznitelikleri azaltarak doğruluğu arttırmak, bir çözümün anlaşılabilir ve gerçekçi olabilme olasılığını arttırmak için kullanılmaktadır [4]. Özel bir özellik çıkarımı olarak söylenebilen öznitelik seçimi, boyutların azaltılması için verilerin ön işlemden geçirilmesi aşamasından biridir [5]. Herhangi bir dönüşüm olmaksızın mevcut özelliklerin bir alt kümesini seçmektedir.

İnşaat sektörü, genelde bilişim teknolojilerinin daha geç uygulandığı sektörlerden biri [6] olmakla birlikte bu sektörün günümüzde popülerleşmesiyle bilişim teknolojilerine olan ihtiyacı daha da artmaktadır. YZ teknolojisinin inşaat sektöründe uygulandığı alanlar incelendiğinde inşaat alanlarını daha güvenli hale getirmek ve iş kazalarının azaltılmasını sağlamak için bu teknolojiden faydalanıldığı gözlenmektedir [7]. Ayrıca kule vinçlerinin uydu ve internet üzerinden gözetlenmesi, arıza takip ve kontrolünün sağlanmasında; deprem yüklerinin algılanmasında; yalıtım malzemelerinin kalitesinin tespitinde; proje tasarımında; optimizasyonda; yapı yaklaşık maliyet hesaplarında; etkin karar alma sürecinde; inşaat maliyetlerinin tahmin edilmesinde kullanıldığı da gözlenmektedir [8].

Bu çalışmanın amacı, öncelikle yapım yönetiminde sıklıkla kullanılan ve başarılı olan yapay zekâ yöntemlerini belirlemek ve belirlenen bu yöntemi yapım yönetiminin önemli bir çalışma konusu olan çalışanların liderlik algılarının tahmin edilmesi konusuna uygulayabilmektir. $\mathrm{Bu}$ sebeple, bu çalışmada çalışanların liderlik algısının belirlenmesi ve tahmin edilmesi amacıyla anketler aracılığı ile toplanarak hazırlanmış bir veri seti oluşturulmuş, bu veri setinde öznitelik seçim yöntemlerinden yapay zekâ tabanlı genetik algoritma kullanılarak daha belirgin öznitelikler seçilmiş ve sınıflandırma algoritmaları ile çalışanların liderlik algısının tahmini gerçekleştirilmiştir.

Çalışmanın ilk bölümünde konu ile ilgili giriş yapılmış, yapay zekânın tanımına, yöntemlerine, nerelerde ne amaçla kullanıldığına ve inşaat 
sektöründeki kullanım alanlarına kısaca değinilmiştir. Ardından öznitelik seçiminin ne olduğu, ne amaçla kullanıldığ 1 ve bu çalışmada neyi hedeflediğinden bahsedilmiştir. Çalışmanın ikinci bölümünde yapım yönetiminde YZ kullanımı ile ilgili Türkiye'de yapılmış olan 20032018 yıllarını kapsayan son 15 yıllık süreçte gerçekleştirilen çalışmaların literatür incelemesi [9-24] detaylı bir şekilde yapılarak kullanılan yöntemleri de içerecek şekilde özeti tablo halinde sunulmuştur. Ayrıca bu bölümde literatürde bahsi geçen yöntemlerden başarılı olanlar belirlenerek bu çalışmanın amacını oluşturan öznitelik seçimi için kullanılacak algoritmaya karar verilerek veri seti hakkında kısaca bilgi verilmiştir. Çalışmanın üçüncü bölümünde özniteliklerden hangilerinin liderlik algısının belirlenmesi konusunda diğerlerinden daha etkili olduğu açıklanmış ve uygulanan öznitelik seçimi algoritması ile elde edilen sonuçlar paylaşılmıştır. Çalışmanın son bölümünde ise YZ'nin inşaat yapım yönetimindeki kullanımının önceki çalışmalarda hangi alanlarda ve ne amaçla yapıldığı araştırılarak ortaya konulması ile gelecekteki çalışmalara 1 şık tutması hedeflenmiştir.

\section{2. ÖNCEKİ ÇALIŞMALAR}

İnşaat Sektöründe Yapay Zekâ yönteminin kullanılması ile ilgili çalışmalar, son yıllarda giderek artan bir hızla yaygınlaşmaya başlamıştır. YZ inşaat sektöründe yeni kullanılmaya başlanıldığı için geçmiş yıllarda Türkiye özelinde yapılan çok fazla çalışma bulunmamaktadır. İnşaat sektöründe son yıllarda yapılan çalışmalardan Türkiye özelinde yapım yönetimi alanında yapılan çalışmalar bu bölümde incelenmektedir.

Günaydın ve Doğan [9], çalışmalarında Türkiye'deki 30 adet 4-8 katlı betonarme yapılar için 8 adet tasarım parametresinin içerisinde bulunduğu oluşturulan binanın erken fiyat tahmin analizini YZ tekniklerinden biri olan YSA modelini kullanarak gerçekleştirecek bir model geliştirmişlerdir. $\mathrm{Bu}$ ağ modelinin maliyet tahmininin doğruluk oranı yaklaşık \%93 olarak gözlenmiştir.
Doğan ve arkadaşları [10] çalışmalarında 9 adet inşaat projesi, 8 farklı yapı özelliği kullanarak 3 farklı optimizasyon yöntemi ile elektronik tablo tabanlı bir vaka temelli muhakeme (CBR) tahmin modelinde kullanılan öznitelik ağırlıklarını belirlemeye çalışmışlardır. Çalışma sonucunda YZ tekniklerinden biri olan Genetik Algoritma optimizasyon yöntemi ile ortalama hata oranı $\% 16,23$ olarak hesaplanmış ve diğer yöntemlere göre daha başarılı olduğu tespit edilmiştir.

Demirel [11] çalışmasında Türkiye Konut Yapı Kooperatifleri Birliği (TÜRKKONUT) tarafından yaptırılan konutların maliyetlerinin tahmin edilmesini amaçladığı çalışmasında $\mathrm{YZ}$ tekniklerinden biri olan YSA yöntemini kullanmıştır. Maliyetler hesaplanırken betonarme taşıyıcı sisteme benzer nitelikteki çok katlı toplu konut projelerinin çizimleri ve metrajlarından faydalanılmıştır. Her bir inşaat projesinin inşaat maliyeti, Çevre ve Şehircilik Bakanlığı 2005 Yılı Birim Fiyat Rayiçleri esas alınarak hesaplanmış; tip kat alanları, yapı yükseklikleri ve toplam dış cephe alanları değerleri ile birlikte, oluşturulan çok katmanlı, geri beslemeli, danışmanlı öğrenme özelliklerinde yapılandırılan YSA'ya veri olarak girilmiştir. Yapılan öğretme ve test etme işlemlerinin ardından başka projelere ait verilerin ağa girilmesi ile bu projelere ait maliyet tahminleri yaptırılmıştır. Çalışma sonucunda YSA ile Regresyon Analizi ve Birim Fiyat Yöntemi (BFY) karşılaştırılmış ve YSA'nın daha az hata ve $\% 95,58$ doğruluk ile maliyet tahmini yaptığ 1 gözlenmiştir.

Dikmen ve arkadaşları [12] çalışmalarında uluslararası inşaat projelerinde sözleşme bedeliyle ilgili riski YZ tekniklerinden biri olan Bulanık Mantık yöntemi ile değerlendirmişlerdir. Sözleşme bedeli riski, ülke ve proje seviyesinde iki risk grubuna ayrılmıştır. Ülke ve proje seviyesi olmak üzere 2 risk grubunda sınıflandırılan sözleşme bedeli riskinin her bir risk büyüklükleri ayrı ayrı hesaplanmış, yüklenicinin söz konusu ülke veya proje ile ilgili deneyimleri ve sözleşme şartları da göz önünde bulundurularak bu grupların sonuç risk büyüklükleri tespit edilmiştir ve bulanık mantık yöntemi ile hesaplanmıştır. Çalışma sonucunda yüklenicinin ülke veya projedeki deneyiminin ve 
sözleşmedeki şartlarının risk üzerinde diğer risk faktörlerine göre daha etkili olacağı, eğer yüklenicinin benzer projelerde deneyimi var ise beklenen proje riskinin düşük olacağı ve yüklenicinin bu proje için diğer firmalara göre daha avantajlı duruma geleceği belirtilmiştir.

Uğur [13] çalışmasında betonarme taşıyıcı sistemli ve benzer nitelikteki çok katlı toplu konut projelerinin inşaat maliyetlerini YZ tekniklerinden biri olan YSA yöntemini kullanarak tahmin etmiştir. Oluşturulan YSA Modeli çok katmanlı, geri beslemeli, danışmanlı öğrenme özelliklidir. Çalışma sonucunda YSA çıktılarını Birim Fiyat Yöntemi ve Regresyon Analizi ile yapılan maliyet hesaplamaları ile karşılaştırmış, YSA ile elde edilen hata oranı ortalama \%4,79 iken, Regresyon ile elde edilen hata oranı ortalama \%16,58 bulunmuş, YSA'nın gerçeğe daha yakın ve uygulanabilir sonuçlar sağladığı gözlenmiştir.

Kuşan ve Özdemir [14] çalışmalarında inşaat projelerinde risk yönetimi ve analizi konusunda kullanılan yazılımları açıklayıp, literatürde yer alan modelleri incelemişlerdir. Çalışma sonucunda, risklerin proje üzerindeki etki büyüklüğünün belirlenmesi için YZ tekniklerinden biri olan Bulanık Mantık teorisi, AHP (Analytic Hierarchy Process) vb. gibi yöntemlerin risk analiz ve yönetim modellerinde son yıllarda daha fazla kullanılabilir hale geldiği gözlenmiştir.

Uğur ve arkadaşları [15] çalışmalarında tek katlı yığma konut yapılarının inşaat maliyetlerinin YZ tekniklerinden biri olan YSA kullanılarak tahmin etmeye çalışmışlardır. Çevre ve Şehircilik Bakanlığı Birim Fiyat Rayiç verileri temel alınarak oluşturulan YSA modeli ile inşaat maliyetleri belirlenmiştir. Çalışma sonucunda \%5,87'lik hata payı ile kabul edilebilir maliyet değerleri elde edilmiştir.

Bahadır ve Hanedaroğlu [16], çalışmalarında cam elyaf katkılı cephe kaplama elemanlarının farklı mimarilere sahip 100 adet cephenin metraj1 çıkarılarak pazarlanmasında teklif fiyatının YSA yardımıyla tahmin edilmesi amaçlanmıştır. Çalışma sonucunda YSA yöntemi kullanılarak en düşük ortalama karesel hata değeri 0,000245 olarak elde edilmiştir.

Bisen ve Dikmen [17] çalışmalarında inşaat projelerindeki bütçe çalışmalarında, proje karakteristik özelliklerinden kaynaklanan belirsizliklerin aşılmasında, YZ yöntemlerinin kullanılabilirliğini araştırmışlardır. Çalışma kapsamında YZ tekniklerinden Bulanık Mantık yöntemi proje karakteristik özelliklerinden kaynaklanan belirsizliklerin derecesinin tespitinde kullanılmıştır. Çalışma sonucunda, proje karakteristik özelliklerinden kaynaklanan belirsizlik seviyesinin tespitinin YZ yöntemleri ile gerçekleştirilmesinin daha uygulanabilir olduğu görüşüne varılmıştır.

Altun ve Akçamete [18] çalışmalarında inşaat projelerinin zaman ve maliyet problemlerinin sezgisel algoritmalarla modellenip çözümlenmesi konusuna değinmişlerdir. Çalışmalarında YZ tekniklerinden sezgisel ve zeki algoritmalardan Yapay Arı Kolonisi Algoritmasını kullanmışlardır. Çalışma sonucunda, elde edilen çıktıların gerçek değerlere daha yakın olduğu sonucuna varmışlardır.

Andaç ve Oral [19] çalışmalarında işçi verimliliklerini tahmin edebilmek amaciyla geri beslemeli YSA yöntemini kullanmışlar, bu yönteme YZ tekniklerinden sezgisel bir algoritma olan Yapay Arı Kolonisi Algoritmasını entegre ederek ağın eğitimini gerçekleştirmişlerdir.

Bayram ve arkadaşları [20] çalışmalarında, YZ tekniklerinden olan Çok Katmanlı Algılayıcı (MLP) ve Radyal Tabanlı Fonksiyon (RBF) teknikleri ile elde edilen inşaat maliyet tahminlerini karşılaştırmışlardır. Çalışma sonucunda, çıtılar Birim Alan Maliyet Yöntemi ile karşılaştırılmış, her iki yapay sinir ağı yönteminin de birim alan maliyet yönteminden \%28,73'lük bir varyans ile daha iyi performans gösterdiği, ancak radyal tabanlı fonksiyonun da çok katmanlı algılayıcıdan \%1,11'lik bir varyans ile daha başarılı olduğu kanaatine varılmıştır.

Bayram ve Al-Jibouri [21] çalışmalarında, bina projelerinin maliyetlerini tahmin etmek için 
geleneksel olmayan, YZ tekniklerinden sezgisel optimizasyon ve veri madenciliğinde de kullanılan beş farklı güncel yöntemi, YZ tekniklerinden Çok Katmanlı Algılayıcı (MLP), YZ tekniklerinden Radyal Tabanlı Fonksiyon (RBF), Izgara Bölümleme Algoritması (GPA), Referans Sinıfı Öngörme (RCF) ve Regresyon Analizi (RA), bir arada kullanmışlardır. Çalışma sonucunda Referans Sınıfı Öngörme (RCF) ve Regresyon Analizi (RA) tekniklerinin diğer metotlara göre daha gerçekçi tahminler ürettiği gözlenmiştir.

Koğ ve Yaman [22] çalışmalarında, e-ihale süreçlerindeki sorunların giderilerek verimliliğin artırılmasına dair iş süreç modelleri oluşturulmasını amaçlamışlardır. $\mathrm{Bu}$ iş süreç modellerinin YZ ile benzetim yöntemlerinden Petri Ağları yöntemi ile destekleyip, işveren ve yüklenici açısından fayda optimizasyonunu gerçekleştirecek algoritmalara değinerek örnek bir olay üzerinden sistemi test etmişlerdir.

Dobrucalı ve Demir [23] çalışmalarında kamu kurumları açısından yatırım bütçelerinin planlanması alanında yapılan ön çalışmalara kazanım sağlayacak, bunun dışında ihaleye teklif verecek isteklilere yap1 maliyeti konusunda ön bilgi verecek, az sayıda değişkenin kullanıldığı, hızlı ve gerçeğe oldukça yakın bir genel tahmin metodu olan YZ yönteminin uygulanabilirliğini araştırmışlardır. Çalışmada 2011-2016 yılları arasındaki 120 proje, toplam inşaat alanı değişkeni ve üç adet sabit yap1 birim ölçüleri üzerinden, genetik algoritma programı ile analiz edilmiş ve yaklaşık maliyet tahmini yapılmıştır. $\mathrm{Bu}$ bahsedilen projelerin ihalesi kamu kurumları tarafından gerçekleştirilmiştir. Çalışmanın sonucunda, yaklaşık maliyet belirleme kat sayısının (R2) eğitim verilerinde 0,98 , test verilerinde ise 0,95 olarak bulunarak tahmin edilebildiği gözlenmiştir.

Kaya Keleş ve Keleş [24] çalışmalarında Türkiye'de ve dünyada gittikçe gelişmekte olan yapım yönetimi konusunda veri madenciliği ve YZ tekniklerinden olan sezgisel optimizasyon algoritmaları ile ilgili 2012-2017 y1lları arasındaki literatür araştırmalarını incelemişler ve detaylı bir tablo üzerinde kronolojik olarak göstermişlerdir.
Çalışma sonucunda, bahsi geçen algoritmaların kullanılması ile ham verinin yeterince elde edilebildiği bir sektör olan inşaat sektöründe ilgili çalışmaların yapılması aracılığıyla daha faydalı sonuçlar elde edilebileceğini belirtmişlerdir.

\section{MATERYAL VE METOT}

Çalışmanın bu bölümünde Türk İnşaat sektöründe Yapım Yönetimi alanında YZ Yöntemlerinin kullanım alanları araştırılmış ve amaç gruplarına göre sinıflandirılarak bir tablo üzerinde önemi incelenmiştir. $\mathrm{Bu}$ sayede, YZ metotlarının yapım yönetimi alanında kullanıldığı çalışmalar karşılaştırılarak ileriki çalışmalara ön bilgi sunması hedeflenmiştir.

Türkiye'deki inşaat sektörü yapım yönetimi dalındaki yukarıda da bahsi geçen çalışmaların detaylı bir şekildeki gösterimi çalışma yılları, kullanılan YZ Yöntemleri ve yapılan çalışmanın konusunu/hangi amaçla yapıldığını, başarı oranlarını da içerecek şekilde amaç gruplarına göre sıralanmakta ve Çizelge 1'de sunulmaktadır. Çizelge 1, Bulgular bölümünde yorumlanarak açıklanmıştır.

Çalışma kapsamında en başarılı sınıflandırıcıyı tespit edebilmek amaciyla siklıkla tercih edilen ve Çizelge 1'de kullanılan sınıflandırıcılardan Naive Bayes, Destek Vektör Makineleri (SMO), Çok Katmanlı Algılayıc1 (MLP), Radyal Tabanlı Fonksiyon Ağları (RBF Network), Karar Tablosu (Decision Table) ve J48 Karar Ağacı hem veri seti üzerinde hem de yine Çizelge 1'deki literatürlerde kullanılıp daha başarılı sonuçlar üreten ve Şekil 1'de sunulan Genetik arama yöntemi ile Çizelge 2'deki özniteliklere öznitelik seçimi yapıldıktan sonra Çizelge 3'te gösterilen özniteliklerden oluşan veri seti üzerinde karşılaştırılmıştır.

1970'li yıllarda John Holland tarafından Genetik Algoritma (GA) yöntemi geliştirilmiştir [25]. Goldberg'in kitabında [26] kitabında genetik algoritma ile ilgili 83 adet farklı uygulamaya yer vererek genetik algoritmanın öznitelik seçimi dâhil çeşitli konularda kullanıldığını göstermiştir. GA, 
popülasyon tabanlı bir arama ve optimizasyon yöntemidir. Genetik Arama, Goldberg'in [26] bahsi geçen kitabında açıklanan basit genetik algoritmayı kullanarak bir arama gerçekleştirmektedir. Öznitelik seçiminde, Genetik Algoritma (GA) rastgele seçim algoritması olarak kullanılmaktadır; öznitelik seçimi durumunda genellikle gerekli olan geniş arama alanlarını etkili bir şekilde araştırmaktadır. Yerel, açgözlü arama gerçekleştiren birçok arama algoritmasının aksine GA global bir arama gerçekleştirmektedir.

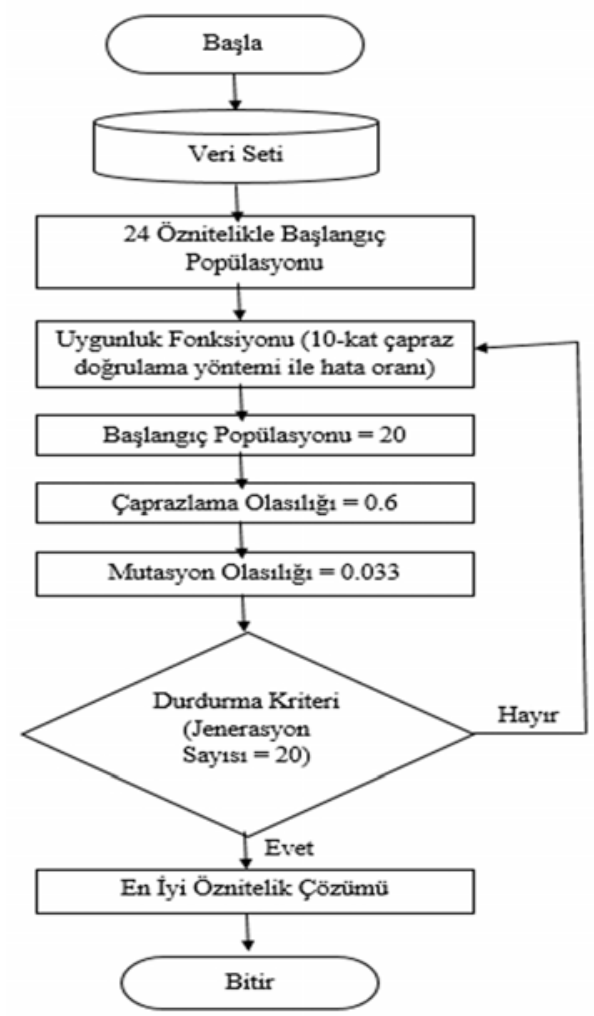

Şekil 1. Kullanılan genetik algoritma yönteminin ve parametrelerinin akış şeması

Çizelge 1. Yapay zekâ yöntemlerinin literatürdeki yapım yönetiminde uygulanmasıyla elde edilen bulguların karșılaştırmalı olarak detaylı incelenmesi

\begin{tabular}{|c|c|c|c|c|}
\hline Çalışma & Yılı & Yapay Zekâ Yöntemi & Çalışma Amacı & $\begin{array}{c}\text { Başarı Oranı (BO)/ } \\
\text { Ortalama Hata Oranı } \\
\text { (OHO) }\end{array}$ \\
\hline [9] & 2004 & Yapay Sinir Ağları & $\begin{array}{c}\text { Erken Fiyat Tahmin Analizi/ Maliyet } \\
\text { Tahmini }\end{array}$ & BO: Yaklaşık \%93 \\
\hline [11] & 2007 & Yapay Sinir Ağları & Maliyet Tahmini & BO: $\% 95,58$ \\
\hline [13] & 2007 & Yapay Sinir Ağları & Maliyet Tahmini & $\begin{array}{c}\mathrm{BO} / \mathrm{OHO} \\
\text { Paylaşılmamış }\end{array}$ \\
\hline [15] & 2011 & Yapay Sinir Ağları & Maliyet Tahmini & OHO: $\% 5,87$ \\
\hline$[18]$ & 2014 & Sezgisel Algoritma & $\begin{array}{l}\text { Zaman ve Maliyet Problemlerinin } \\
\text { Çözümü }\end{array}$ & Sonuca Ulaşılamadı \\
\hline$[20]$ & 2016 & MLP ve RBF & Maliyet Tahmini & OHO: $\% 0,28$ \\
\hline$[21]$ & 2016 & MLP ve RBF & Maliyet Tahmini & Sonuca Ulaşılamadi \\
\hline
\end{tabular}


Çizelge 1 (devam)

\begin{tabular}{|c|c|c|c|c|}
\hline [23] & 2017 & Genetik Algoritma & Yaklaşık Maliyet Tahmini & BO: $\% 95-\% 98$ \\
\hline [16] & 2012 & Yapay Sinir Ağları & Teklif Fiyatı Tahmini & Sonuca Ulaşılamadi \\
\hline [22] & 2016 & $\begin{array}{c}\text { Benzetim Yöntemi / Petri } \\
\text { Ağları }\end{array}$ & E-İhale Süreç Verimliliği & $\begin{array}{c}\mathrm{BO} / \mathrm{OHO} \\
\text { Paylaşılmamış } \\
\end{array}$ \\
\hline [12] & 2007 & Bulanık Mantık & $\begin{array}{c}\text { Uluslararası İnşaat Projelerinde } \\
\text { Sözleşme Bedeliyle İlgili Risk Tahmini }\end{array}$ & Sonuç Paylaşılmamış \\
\hline [14] & 2008 & Bulanık Mantık & $\begin{array}{l}\text { Risk Analiz ve Yönetim Modellerinde } \\
\text { Literatür Taraması }\end{array}$ & $\begin{array}{l}\text { Sadece Literatür } \\
\text { Taranmıș }\end{array}$ \\
\hline$[17]$ & 2012 & Bulanık Mantık & $\begin{array}{c}\text { Proje Karakteristik Özelliklerinden } \\
\text { Kaynaklanan Belirsizlik Seviyesinin } \\
\text { Tespiti } \\
\end{array}$ & Uygulama Yapılmamış \\
\hline [24] & 2017 & Sezgisel Algoritma & $\begin{array}{c}\text { Yapım Yönetiminde Literatür } \\
\text { Taraması }\end{array}$ & $\begin{array}{c}\text { Sadece Literatür } \\
\text { Taranmış } \\
\end{array}$ \\
\hline [19] & 2014 & Sezgisel Algoritma & İşçi Verimlilikleri Tahmini & Sonuca Ulaşılamadı \\
\hline$[10]$ & 2006 & Genetik Algoritma & $\begin{array}{c}\text { Elektronik Tablo Tabanlı Bir Vaka } \\
\text { Temelli Muhakeme (CBR) Tahmin } \\
\text { Modelinde Kullanılan Öznitelik } \\
\text { Ağırlıklarını Üretme }\end{array}$ & OHO: $\% 16,23$ \\
\hline
\end{tabular}

Çizelge 2. Veri setini oluşturan öznitelikler

\begin{tabular}{|c|c|c|}
\hline Öznitelik Adı & $\begin{array}{l}\text { Aldığı } \\
\text { Farklı } \\
\text { Değer } \\
\text { Sayısı }\end{array}$ & $\begin{array}{c}\text { Öznitelik Tanımı ve İstatistiki Bilgisi (Her bir öznitelik için } \\
102 \text { örnek sayısı) }\end{array}$ \\
\hline gorev & 11 & $\begin{array}{c}\text { Boyacı (17), Demirci (1), Doğalgaz Döşemeci (4), Formen (13), } \\
\text { İşçi (23), Kalıpçı (4), Parke Ustası (5), Seramikçi (3), Sıvacı (17), } \\
\text { Tesisatçı (10), Usta (5) }\end{array}$ \\
\hline doğum_yeri & 14 & $\begin{array}{l}\text { Adana (80), Adıyaman (1), Ağrı (1), Batman (1), Bingöl (2), } \\
\text { Bitlis (1), Erzurum (1), Kahramanmaraş (2), Mardin (4), Mersin } \\
\text { (1), Muş (1), Osmaniye (4), Şanlıurfa (2), Sivas (1) }\end{array}$ \\
\hline cinsiyet & 2 & Erkek $(102)$ ve $\operatorname{Kad} ı(0)$ \\
\hline yas & 5 & 25 ve altı $(1), 26-40(42), 41-55(58), 56-65(1), 65$ ve üzeri $(0)$ \\
\hline eğitim & 6 & $\begin{array}{l}\text { Mezun Değil (1), İlkokul (48), Ortaokul (45), Lise (8), Üniversite } \\
\text { (0), Lisansüstü (0) }\end{array}$ \\
\hline maas & 4 & 1500 ve alt1 (54), 1501-2000 (38), 2001-2500 (7), 2501-3000 (3) \\
\hline tecrube & 4 & 1 y1ldan az (0), 1-5 y1l (4), 5-10 y1l (31), 10 yıldan fazla (67) \\
\hline $\begin{array}{l}\text { benzer_islerdeki_ } \\
\text { tecrube }\end{array}$ & 4 & 1 yıldan az (0), 1-5 yıl (3), 5-10 yıl (31), 10 yıldan fazla (68) \\
\hline calisma_suresi & 4 & 1 yıldan az (4), 1-5 yıl (19), 5-10 y1l (55), 10 yıldan fazla (24) \\
\hline bölge & 7 & $\begin{array}{c}\text { Marmara (0), Ege (0), Akdeniz (102), İç Anadolu (0), Karadeniz } \\
\text { (0), Güney Doğu Anadolu (0), Doğu Anadolu (0) }\end{array}$ \\
\hline $\begin{array}{c}\text { sefiyle_calisma_ } \\
\text { suresi }\end{array}$ & 4 & 1 yıldan az (13), 1-5 yıl (24), 5-10 yıl (46), 10 yıldan fazla (16) \\
\hline ekip_kisi_sayisi & 5 & $\begin{array}{c}10 \text { 'dan az (66), 11-50 (32), 51-100 (3), 101-200 (0), } 201 \text { 'den fazla } \\
(1)\end{array}$ \\
\hline pozisyon & 6 & $\begin{array}{c}\text { Usta (52), Kalfa (0), İşçi (37), Formen (13), Tekniker (0), } \\
\text { Teknisyen (0) }\end{array}$ \\
\hline
\end{tabular}


Çizelge 2 (devam)

\begin{tabular}{|c|c|c|}
\hline altyapi & 2 & Evet (83), Hayır (19) \\
\hline ustyapi & 2 & Evet (29), Hayır (73) \\
\hline tesisat & 2 & Evet (86), Hayır (16) \\
\hline ucret_yonetimi & 4 & Yevmiye Usülü (0), Haftalık (3), Aylık (99), Götürü Bedel (0) \\
\hline mesai & 2 & Evet (62), Hayır (40) \\
\hline ulasim_mesafesi & 3 & Şantiye içi (1), 30 dakikadan az (88), 30 dakikadan fazla (13) \\
\hline $\begin{array}{c}\text { calisilan_gun_ } \\
\text { sayisi }\end{array}$ & 7 & $1(0), 2(0), 3(0), 4(0), 5(0), 6(41), 7$ (61) \\
\hline $\begin{array}{c}\text { günlük_calisma_ } \\
\text { suresi }\end{array}$ & 12 & $1(0), 2(0), 3(0), 4(0), 5(0), 6(0), 7(1), 8(12), 9(11), 10$ (75), \\
\hline $\begin{array}{c}\text { günlük_mola_ } \\
\text { suresi }\end{array}$ & 7 & 1 (38), 2 (63), 3 (0), 4 (0), 5 (0), 6 (0), 7 (1) \\
\hline motivasyon & 2 & Düşük (49) ve Yüksek (53) \\
\hline $\begin{array}{c}\text { lideregore_ } \\
\text { liderliktipi }\end{array}$ & 3 & Dönüşümcü (84), Etkileşimci (18) ve Pasif-Kaçınan (0) \\
\hline $\begin{array}{c}\text { sinıf (calisanagore_ } \\
\text { liderlik_tipi) }\end{array}$ & 3 & Dönüşümcü (81), Etkileşimci (20) ve Pasif-Kaçınan (1) \\
\hline \multicolumn{2}{c}{} \\
\hline
\end{tabular}

Çizelge 3. Öznitelik seçimi yapılmadan ve Genetik algoritma metodu kullanılarak öznitelik seçimi yapıldıktan sonra farklı sınıflandırıcılar ile sınıflama yapıldığında elde edilen sonuçların karşılaştırması

\begin{tabular}{|l|c|c|}
\hline Sınıflandırıcı & $\begin{array}{c}\text { Ham Veri Seti için Doğruluk } \\
\text { Oranı }\end{array}$ & $\begin{array}{c}\text { Öznitelik Seçimi Yapılarak Oluşturulan } \\
\text { Veri Seti için Doğruluk Oranı }\end{array}$ \\
\hline Naive Bayes & $\% 71,57$ & $\% 77,45$ \\
\hline SMO & $\% 69,61$ & $\% 74,51$ \\
\hline Multilayer Perceptron & $\% 67,65$ & $\% 73,53$ \\
\hline RBF Network & $\% 74,51$ & $\% 76,47$ \\
\hline Decision Table & $\% 75,49$ & $\% 75,49$ \\
\hline J48 & $\% 75,49$ & $\% 78,43$ \\
\hline
\end{tabular}

Naive Bayes algoritması, olasılık hesabına dayalı bir algoritmadır. Eğitim veri setindeki verileri kendi olasılık formülüne göre hesaplayıp, her durum için çıkardığı oran olasılıklarına göre test veri setindeki verileri sınıflandırarak çalışmaktadır [27]. Bu sebeple öğretilmiş veri miktarı ne kadar çoksa, test verisinin sınıfını tahmin etme oranı da o kadar yüksek olmaktadır. $\mathrm{Bu}$ sinıflandırma yönteminde, özniteliklerin birbirinden bağımsız olması çok önemlidir, çünkü birbirini etkileyen öznitelikler olursa olasılık değerini hesaplamak zorlaşacaktır.

Bir Destek Vektör Makinesi (SVM) algoritması, sınıflandırma ve regresyon analizi için kullanılan istatiksel öğrenme teorisine dayalı bir denetimli öğrenme algoritmasıdır. Sınıflandırma problemini kareli optimizasyon problemine dönüştürüp çözme yeteneğine sahip SVM'nin amacı farklı sınıflara ait destek vektörleri arasındaki uzaklığı maksimize 
etmektir. Weka'da bulunan SMO ise bir destek vektör sınıflandırıcıyı eğitmek için John Platt'ın sıralı minimum optimizasyon algoritmasını uygulayarak çalışan bir algoritmadır [28]. SMO, global olarak tüm eksik değerleri değiştirmekte ve nominal nitelikleri ikili niteliklere dönüştürmektedir [29]. Normalizasyon olarak da tüm nitelikleri varsayılan hale getirmektedir, yani bu durumda çıktıdaki katsayılar orijinal veri setine değil bu normalize edilmiş veri setine dayanmaktadır [29].

Çok Katmanlı Algılayıcı (MLP) geri-yayılım öğrenme sistemini kullanan ve siklıkla sınıflandırma için kullanılan bir yapay sinir ağının bir sınıfıdır. Bir giriş katmanı, bir veya daha fazla saklı katman ve bir çıkış katmanından oluşan MLP ağın eğitimi, tanımlanan hata fonksiyonunun minimizasyonu şeklinde ifade edilen bir süreçtir. MLP'de her bir çıkış farklı bir ikili sınıfa karşılık gelmektedir. MLP, WEKA'nın Optimizasyon sınıfını kullanan bir gizli katman ile çok katmanlı bir algılayıcıyı eğitmektedir [28]. MLP, çıkış katmanında, sigmoid fonksiyonu sınıflandırma için kullanmaktadır. A $\breve{g}$ ayrıca eğitim süresi boyunca izlenebilmekte ve değiştirilebilmektedir [28].

Radyal Tabanlı Fonksiyon (RBF), girdi veri kümesinin özel olarak belirli bir bölgesine düşen değerler için en büyük değerini alan ve bu noktadan uzaklaştıkça daha küçük değerler üreten fonksiyonlar olup denetimli öğrenme kapsamında değerlendirilen ileri beslemeli bir YSA modelidir [28]. RBF, normalleştirilmiş bir Gauss radyal temel fonksiyon ağını Weka'da uygulayan bir algoritmadır. Temel fonksiyonları sağlamak için kortalama kümeleme algoritmasını kullanmaktadır. Sınıf nominal ise, sınıf başına verilen sayı kümesini kullanmaktadır. Tüm sayısal nitelikleri sıfır ortalaması ve birim varyansına göre standartlaştırmaktadır [28].

Karar Tablosu (Decision Table), Weka'da basit bir karar tablosu çoğunluk sınıflandırıcısı oluşturan ve kullanan bir sinıflandırma algoritmasıdır [30]. Karar tablosu algoritmasında, bir ağaç yapısı oluşturulduktan sonra ağacın yaprakları seviyesinde sinıf etiketleri bulunmakta ve bu yapraklara giden ve kök düğümden çıkan dallar ile de öznitelikler üzerindeki işlemler gerçekleştirilmektedir.

J48 karar ağacı algoritması, temeli C4.5 algoritmalarına dayanan, C4.5 algoritmasının Weka implementasyonu olan bir algoritmadır. J48, budanmış veya budanmamış bir C4.5 karar ağacı oluşturmak için Weka'da olan bir sınıftır [28]. J48, modeli en yüksek bilgi kazancına sahip öznitelik belirlendikten sonra bu öznitelik üzerinden, verilerin bölünmesiyle karara ulaştıran düğümlerin tamamıdır. J48 tüm öznitelikler için metrik bilgi kazancını hesaplayarak en yüksek kazanç seviyesinde düğümü belirlemektedir. $\mathrm{Bu}$ durum ağacin sonuna kadar ardışık şekilde devam etmektedir [31].

$\mathrm{Bu}$ çalışma kapsamında çift taraflı bir anket uygulaması yapılmıştır. Anket veri seti, Adana bölgesindeki 100 inşaat işletmesine ait çalışanların birlikte çalıştıkları şeflerinin liderlik tiplerini belirlediği verileri içermektedir. Bu veri setinde 25 adet parametre, 102 adet örnek bulunmaktadır. Bu parametreler ve istatistiki bilgileri (örnek sayıları) Çizelge 2'de ve Şekil 2 ve 3'te gösterilmektedir.

Çalışmada anket yoluyla elde edilen öznitelikler çalışanın görevi, doğum yeri, cinsiyeti, yaşı, eğitim durumu, maaşı, tecrübesi, benzer işlerdeki tecrübesi, çalışma süresi, çalıştığı coğrafi bölge, şefiyle çalışma süresi, çalıştığı ekipteki kişi sayısı, pozisyonu, altyap1-üstyap1-tesisat iş grubundan hangisinde çalıştığı bilgisi, maaşını aldığı ücret yöntemi, mesai bilgisi, iş yerine olan ulaşım mesafesi, çalıştı̆̆ı gün sayısı, günlük çalışma süresi, günlük mola süresi, motivasyon derecesi, liderinin kendisine göre liderlik tipi, kendisine göre liderinin liderlik tipidir. Çalışan liderlik algısının tahmininde anketlerdeki soruları oluşturan bu parametrelerden hangilerinin diğerlerine göre daha etkili olduğunu belirlemek amacıyla Genetik Algoritma yöntemi ile öznitelik seçimi yapılmıştır. Bu öznitelik seçimi sonucu elde edilen parametreler kullanılarak çalışanın kendisine göre liderinin liderlik tipinin sınıflandırılması sağlanarak çalışanın liderlik algısının tahmini gerçekleştirilmiştir. 


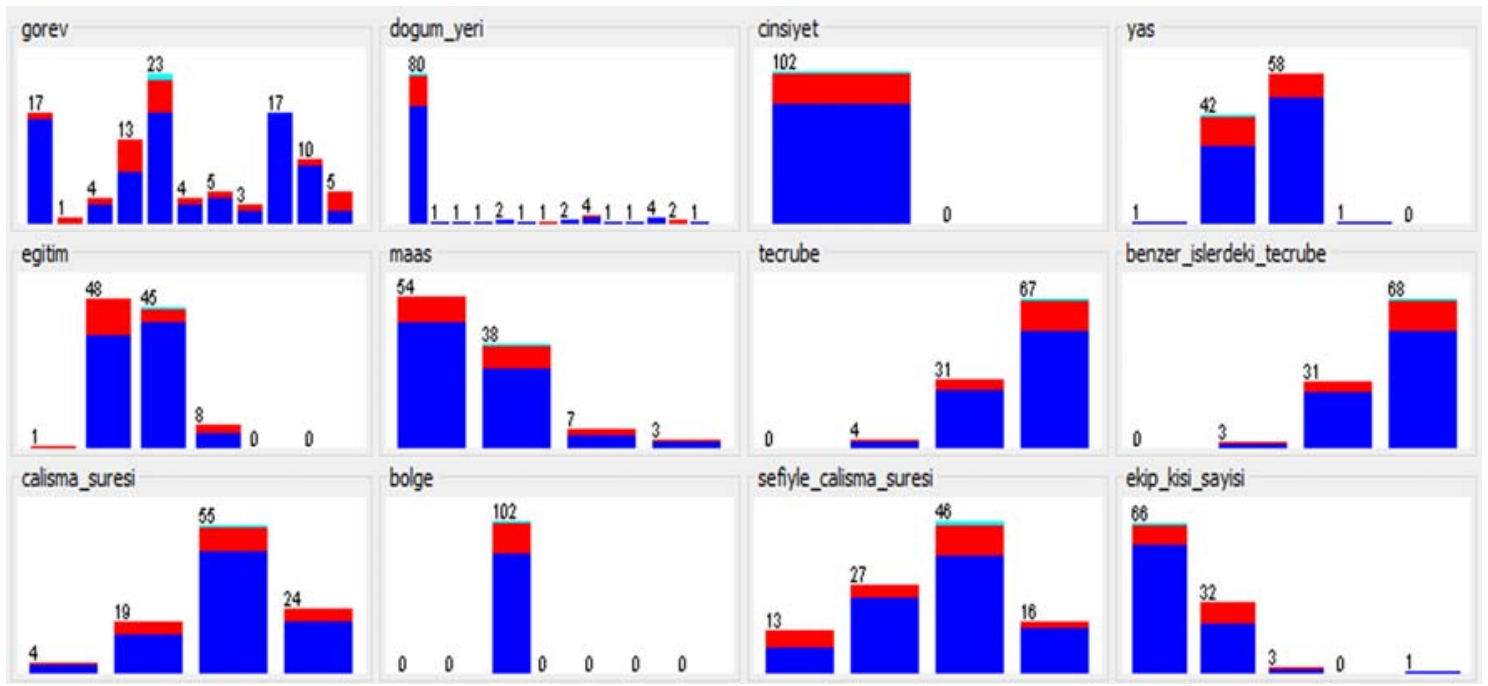

Şekil 2. Kullanılan parametrelerin (görev, doğum yeri, cinsiyet, yaş, eğitim, maaş, tecrübe, benzer işlerdeki tecrübe, çalışma süresi, bölge, şefiyle çalışma süresi, ekip kişi sayısı) istatiksel bilgisi

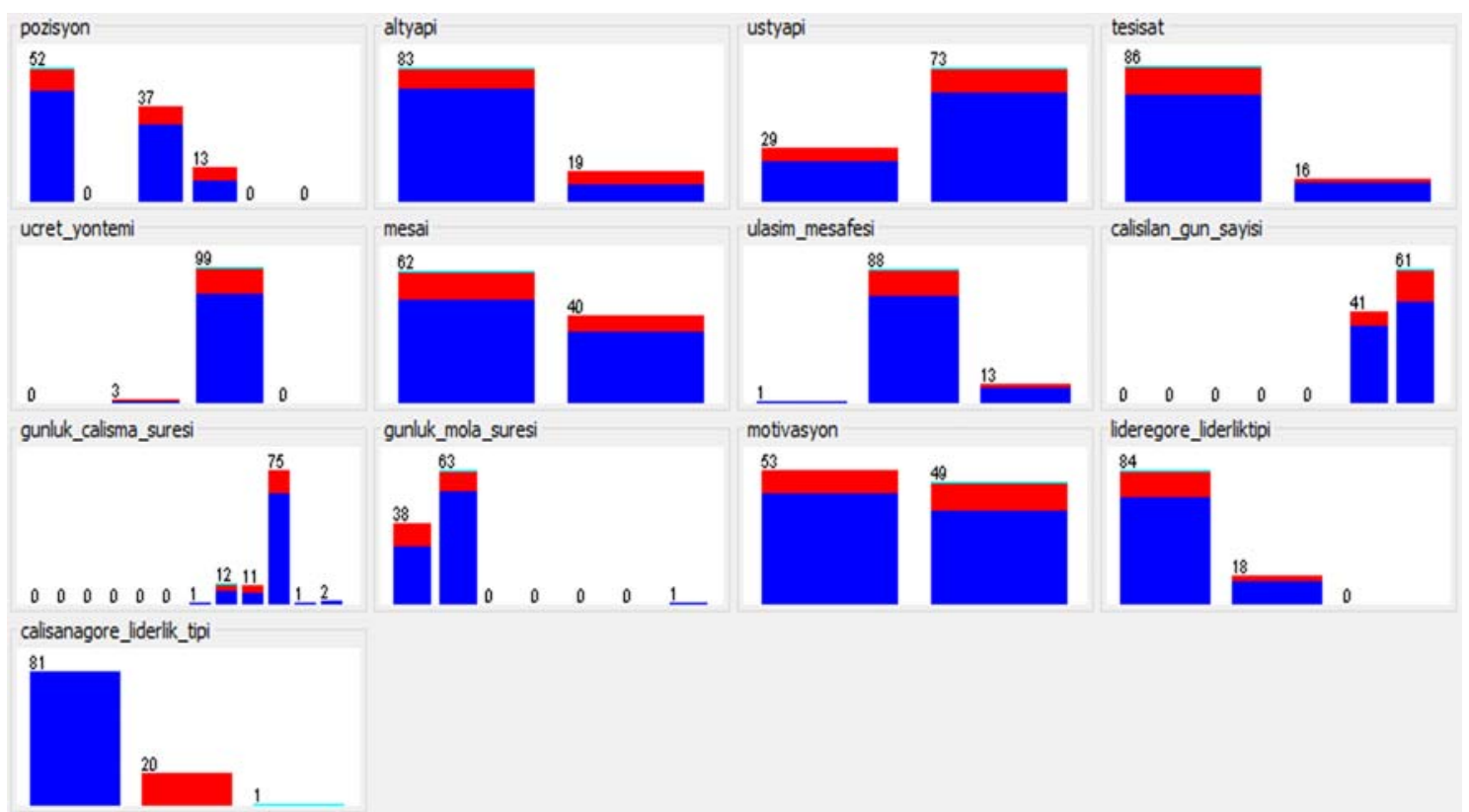

Şekil 3. Kullanılan parametrelerin (pozisyon, altyapı, üstyapı, tesisat, ücret yöntemi, mesai, ulaşım mesafesi, çalışılan gün sayısı, günlük çalışma süresi, günlük mola süresi, motivasyon, lidere göre liderlik tipi, çalışana göre liderlik tipi) istatiksel bilgisi

\section{BULGULAR}

Çizelge 1'den de anlaşılacağı üzerine yapım yönetiminde YZ tekniklerinin uygulama alanı geniş olmakla beraber daha çok maliyet tahmini konusunda başarılı bir şekilde uygulanma imkânı bulduğu gözlenmiştir. Çizelge 1'e göre maliyet tahmini konusunda en düşük başarıyı \%93 
doğruluk oranı ile YSA yöntemi gösterirken, en yüksek başarıyı ise yaklaşık \%98 doğruluk oranı ile genetik algoritma yöntemi göstermektedir.

GA'nın yapım yönetiminde özellikle maliyet tahmini konusundaki başarısı görüldükten sonra, çalışan liderlik algısı konusundaki etkisini ölçmek için bu çalışma kapsamında uygulanan anketlerde çalışanların şeflerinin liderlik tiplerini belirlediği verilerden oluşturulan veri setindeki parametrelerden öncelikle hangilerinin önemli, hangilerinin ise çalışma için daha az önemli olduklarının belirlenmesi, ileriki çalışmalarda çalışan liderlik algısını doğruluk oranı yüksek bir şekilde sınıflayabilmek için gerekmektedir. Bu sebeple WEKA 3.6 yazılımı aracılığı ile Öznitelik Seçimi Yöntemlerinden Genetik Algoritma metodu kullanılarak önemli bulunan öznitelikler seçilmiştir.

Genetik Algoritma yöntemi tüm öznitelikler sisteme girdi olarak verildikten sonra, popülasyon büyüklüğü 20, jenerasyon (nesil) sayıs1 20, çaprazlama olasılığ 0,6 , mutasyon olasılığ 0,033 , rastgele tohum sayısı 1 , nesil raporlarının sıklığı da nesil sayısı kadar yani 20 olacak şekilde varsayılan değerleri alınarak kullanılmış ve en yüksek değerleri veren öznitelikler 10-fold çapraz doğrulama yöntemi kullanılarak elde edilmiş ve çıktı olarak 10 öznitelik seçilmiştir. Bu öznitelikler -gorev, dogum_yeri, yas, eğitim, sefiyle_calisma_suresi, pozisyon, altyapi, ucret_yontemi, $\quad$ gunluk_calisma_suresi, gunluk_mola_suresi-seçilirken $\% 20$ başarı oranının üstünde olan öznitelikler tercih edilmiştir. $\mathrm{Bu}$ çalışmada, öznitelik seçiminde Genetik Algoritma öznitelik seçiminde genellikle gerekli olan geniş arama alanlarını etkili bir şekilde araştıran rastgele bir seçim algoritması olarak kullanılmıştır. Ayrıca, yerel ve açgözlü (greedy) arama gerçekleştiren birçok arama algoritmasının aksine GA global bir arama gerçekleştirmektedir. Böylece bu algoritma, en iyi nüfus üyesini bir sonraki nesle yaymaktadır. Yani bu çalışma için orijinal öznitelik kümesi 24 öznitelik içerdiği için, oluşturulacak rekabet eden aday alt kümelerinin toplam sayısı $2 * 24$ yani 48 'dir. Bu da orta ölçekli bir öznitelik içeren veri seti için oldukça büyük sayıda arama yaptığını göstermektedir. $\mathrm{Bu}$ çalışmada kullanılan Genetik Algoritma yönteminin akış şeması Şekil 1'de verilmektedir.

Genetik Algoritma metodu kullanılarak öznitelik seçimi yapıldıktan sonra farklı sınıflandırıcılar ile sınıflama yapıldığında elde edilen sonuçlar Çizelge 3'te gösterilmektedir. Bu çizelgeye göre, Genetik algoritma metodu kullanılarak öznitelik seçimi yapıldıktan sonra başarı oranı ham veri setine göre arttığı gözlenmiştir. Öznitelik seçimi yapıldıktan sonra daha az öznitelik kullanılarak Naive Bayes, SMO, MLP, RBF ve J48'in başarı oranları ham veri setine göre artarken, Decision Table sınıflayıcısının başarı oranı değişmeyerek bir artma ya da azalma gözlenmemiştir. $\mathrm{Bu}$ çizelgeye göre en yüksek başarıyı da ağaç tabanlı bir algoritma olan J48 algoritması göstermiştir. Sınıflandırma çalışmalarında sıklıkla kullanılan bir algoritma olan J48 algoritması genellikle tahminler konusunda oldukça başarılı bir karar ağacı algoritmasıdır [32]. Bu sebeple çalışmanın devamında sınıflandırma tahmini J48 algoritması kullanarak gerçekleştirilmiştir.

Öznitelik seçimi yapılmadan J48 karar ağacı ile sınıflama yapıldığında elde edilen sonuçlar ile GA metodu kullanılarak öznitelik seçimi yapıldıktan sonra elde edilen sonuçların karşılaştırması ise Çizelge 4'te gösterilmektedir. Bu çizelgeye göre öznitelik seçimi yapılmadan önce çalışan liderlik algısı tahmini \%75,49 doğruluk oranında iken, genetik algoritma ile öznitelik seçimi yapılarak sınıf etiketi hariç 24 öznitelikten 10 özniteliğin daha önemli olduğu yargısına ulaşıldıktan sonra sadece bu öznitelikler kullanılarak elde edilen sinıflandırma tahmini $\% 78,43$ doğruluk oranı olarak belirlenmiştir.

Çizelge 4'teki sonuçlar incelendiğinde ham veri seti sınıflandırılırken yanlış bulunan 25 örnekten 4'ü ilk sınıfta yer alması gerekirken ikinci sınıfta tahmin edilmiştir. Öznitelik seçimi yapıldıktan sonra ise ilk sınıfta olması gereken bu 4 örnekten 3'ü doğru tahmin edilmiştir. Bu da göstermektedir ki, Genetik Algoritma metodu kullanılarak öznitelik seçimi yapıldıktan sonra daha az öznitelik kullanılarak doğru sinıflandırılan örnek sayısı artmakta ve sınıflandırmanın doğruluk oranı yükselmektedir. 
Çizelge 4. Öznitelik seçimi yapılmadan ve Genetik algoritma metodu kullanılarak öznitelik seçimi yapıldıktan sonra J48 karar ağacı ile sınıflama yapıldığında elde edilen sonuçların karşılaştırması

\begin{tabular}{|c|c|c|}
\hline J48 & $\begin{array}{c}\text { Doğru Sınıflandırılan Örnek Sayısı } \\
\text { ve Doğruluk Oranı }\end{array}$ & $\begin{array}{c}\text { Yanlış Sınıflandırılan Örnek Sayısı ve } \\
\text { Doğruluk Oranı }\end{array}$ \\
\hline $\begin{array}{c}\text { Öznitelik Seçimi } \\
\text { Yapılmadan }\end{array}$ & $77(\% 75,49)$ & $25(\% 24,51)$ \\
\hline $\begin{array}{c}\text { Öznitelik Seçimi } \\
\text { Yapılarak }\end{array}$ & $80(\% 78,43)$ & $22(\% 21,57)$ \\
\hline
\end{tabular}

\section{SONUÇLAR VE TARTIŞMA}

Yapılan literatür taraması sonucunda Türkiye'de önemli bir endüstriyi oluşturan inşaat sektöründeki çalışmalarda özellikle son yıllarda YZ ve yöntemleri araştırmacılar tarafindan giderek artan bir ivmeyle kullanılmaktadır. Farklı disiplinlerde pek çok araştırmacı tarafindan yaygın șekilde kullanılan YZ yöntemlerinin inşaat sektöründeki problemlerin ve belirsizliklerin azaltılmasina ve çözülmesine yardımcı olabileceği gözlenmektedir.

YZ yöntemleri literatür taramasinda ve Çizelge 1'de de gösterildiği gibi inşaat sektöründe yapım yönetimi dalında bir çok uygulama alanı bulmaktadır. $\mathrm{Bu}$ alanlar incelendiğinde binaların maliyet tahminlerinin yapılmasında, işçi verimliliklerinin tahmininde, ihale süreçlerinin akıllandırılması ve etkinliğinin arttrılmasında, maliyet-zaman ilişkisinin belirlenmesinde, proje belirsizliklerinin tespitinde, risk analizi ve yönetiminde bu teknolojiden yararlanılıp ilgili sorunlara çözümler üretildiği saptanmıştır. Çizelge 1'den anlaşılacağı üzere YZ Tekniklerinin yapım yönetiminde en çok maliyet tahmini konusunda kullanıldığı ve en çok YSA yönteminin tercih edildiği görülmektedir.

$\mathrm{Bu}$ çalışma kapsamında maliyet tahmini konusunda genetik algoritmanın başarısı görüldükten sonra çalışan liderlik algısı konusunda genetik algoritmanın etkisini ölçmek için yapılan anket çalışması ile sınıflayıcı karşılaştırma deneyinde daha yüksek tahmin edici çıkan ve başarılı bir ağaç tabanlı algoritma olan J48 sınıflayıcısı ile sinıflama işlemi gerçekleştirilmiştir. Sınıflama işlemi için öncelikle hangi özniteliklerin önemli hangilerinin ise daha az önemli olduklarının belirlenmesi gerekmektedir. $\mathrm{Bu}$ sebeple öznitelik seçimi işlemi sırasında Genetik algoritma metodundan faydalanılmıștır. Öznitelik seçimi yapılmadan J48 karar ağacı ile sınıflama yapıldığında elde edilen sonuçlar ile Genetik Algoritma metodu kullanılarak öznitelik seçimi yapıldıktan sonra elde edilen sonuçlar ile karşılaştırılmış, bu karşılaştırma sonucuna göre de öznitelik seçimi yapılmadan önce çalışan liderlik algısı tahmini \%75,49 doğruluk oranında iken, genetik algoritma ile öznitelik seçimi 8 niteliğin daha önemli olduğu yargısına ulaşıldıktan sonra sadece bu öznitelikler kullanılarak elde edilen sınıflandırma tahmini $\% 78,43$ doğruluk oranı olarak belirlenmiş̧ir.

Çalışma sonucunda elde edilen hata oranlarına bakıldığında öznitelik seçimi yapılmadan önce 102 örneklemin 25 tanesinde hatalı siniflandırma yapıldığ 1 ve bu 25 örneklemin de 21 'inin direkt Dönüşümcü Liderlik türü olarak sınıflandırıldığ1 gözükmektedir. Öznitelik seçimi yapıldıktan sonra ise, hatalı sinıflandırılan örneklem sayısının 22'ye düştüğü ancak aynı 21 örneklemin hala Dönüşümcü Liderlik türü olarak sinıflandırıldığı, azalmanın Dönüşümcü Lidelik olması gerekirken Etkileşimci Liderlik olarak sinıflandırıldığ 3 örneklemin öznitelik seçiminden sonra doğru sınıflandırılmasıyla gerçekleştiği gözlenmiştir. Bu hatalı sinıflandırmanın sebebinin öncelikle veri setinin homojen dağılamamasından kaynaklandığı görülmektedir. Diğer bir sebep olarak veri seti hazırlanırken uygulanan anketlerde çalışanların liderlerini değerlendirirken korkarak değerlendirmelerinden dolayı gerçek düşüncelerini belirtememeleri düşünülmektedir. Eğer veri seti bu koşullar altında hazırlanmak durumunda olmasaydı önerilen metodun belki daha farklı öznitelikleri 
seçmesiyle sonuçların daha başarılı olacağı düşünülmektedir.

$\mathrm{Bu}$ açılardan bakıldığında, bu çalışmada sunulan Yapım Yönetimindeki YZ ile ilgili araștırmaların bir arada verilmesinin bu alanda yapılabilecek olan yeni çalışmalara ilham verebileceği düşünülmektedir. Çizelge 1'de verilen çalışmalar 1şı̆̆ında bu makaleyi detaylı bir literatür incelemesi olarak ele alıp çalışan liderlik algısı konusuna uyarlanmasıyla elde edilen başarı göz önünde bulundurularak bundan sonraki araştırmalarda, inşaat proje yönetiminde karşılaşılan sorunlardan olan maliyetlerin doğru hesaplanamaması, çalışan verimliliklerinin yeterince ölçülememesi, liderlik algısının belirlenememesi, etkin karar alma sürecinde yaşanan zorlukların giderilememesi, proje sürelerinde gecikmelerin yaşanması, risk yönetiminin sağlıklı planlanıp uygulanamaması, vb. durumların giderilebilmesinin sağlanabileceği öngörülmektedir. Proje problemlerinin çözümlerinde YZ tekniklerini kullanan Türk inşaat sektörü paydaşlarının yönetimsel açıdan fayda sağlayabileceği düşünülmektedir.

\section{KAYNAKLAR}

1. Adalı, E., 1996. Üretimde Uzman Sistem Çözümü, Proceedings of the First Turkish Symposium on Intelligent Manufacturing Systems, Sakarya, 525-535.

2. Kızılkaya, Y.M., Oğuzlar, A., 2018. Bazı Denetimli Öğrenme Algoritmalarının R Programlama Dili ile Kiyaslanması, Karadeniz Uluslararas1 Bilimsel Dergi, 37(37), 90-98.

3. Gök, M., 2017. Makine Öğrenmesi Yöntemleri ile Akademik Başarının Tahmin Edilmesi, Gazi Üniversitesi Fen Bilimleri Dergisi Part C: Tasarım ve Teknoloji, 5(3), 139-148.

4. Steppe, J., Bauer, K.W., 1997. Feature Saliency Measures, Computers \& Mathematics with Applications, 33(8), 109-126.

5. Tsai, C.F., Chou, J.S., 2011. Data Preprocessing by Genetic Algorithms for Bankruptcy Prediction, 2011 IEEE International Conference on Industrial
Engineering and Engineering Management, Singapore, 1780-1783.

6. Tanyer, A.M., Pekeriçli, M.K., 2008. İnşaat Sektörü İçin Bilgi Teknolojilerindeki Son Gelişmeler, TMH-Türkiye Mühendislik Haberleri, Say1: 451-2008/5, 21-26.

7. Japan's Komatsu Selects NVIDIA as Partner for Deploying AI to Create Safer, More Efficient Construction Sites, https://nvidianews.nvidia.com/news/japanskomatsu-selects-nvidia-as-partner-fordeploying-ai-to-create-safer-more-efficientconstruction-sites, 27.02.2018, 2017.

8. Ödünç, B., 2018. Kule Vinçte Yapay Zeka Teknikleri Kullanılıyor, http://www.insaatdunyasi.com.tr/arsiv/yazi/105 -kule-vincte-yapay-zeka-tekniklerikullaniliyor, 27.02.2018.

9. Günaydın, H.M., Doğan, S.Z., 2004. A Neural Network Approach for Early Cost Estimation of Structural Systems of Buildings, Int. J. Proj. Manag., 22, 595-602.

10. Doğan, S.Z., Arditi, D., Günaydın, H.M., 2006. Determining Attribute Weights in a CBR Model for Early Cost Prediction of Structural Systems, J. Constr. Eng. Manag., 132, 1092-1098.

11. Demirel, Y., 2007. Toplu Konut İnşaat Maliyetlerinin Yapay Sinir Ağları ile Tahmini, J. Fac. Eng. Arch. Selcuk Univ., 22(4).

12. Dikmen, İ., Birgönül, M.T., Han, S., 2007. Using Fuzzy Risk Assessment to Rate Cost Overrun Risk in International Construction Projects, International Journal of Project Management, 25, 494-505.

13. Uğur, L.O., 2007. Yap1 Maliyetinin Yapay Sinir Ağı ile Analizi, Doktora Tezi, Gazi Üniversitesi Fen Bilimleri Enstitüsü, Ankara.

14. Kuşan, H., Özdemir, İ., 2008. İnşaat Projelerinde Risk Yönetimi ve Yapay Zeka Yöntemlerinin Kullanımı, TMH-Türkiye Mühendislik Haberleri, 451(5), 38-43.

15. Uğur, L.O., Baykan, U.N., Korkmaz, S., 2011. Yığma Konutların Maliyet Tahmininde Yapay Sinir Ağlarının (YSA) Kullanılması, 6. İnşaat Yönetimi Kongresi, 25-26-27 Kasım 2011, Bursa TMMOB İnşaat Mühendisleri Odası, 223-234. 
16. Bahadır, Y., Haznedaroğlu, F., 2012. Cephe Kaplama Elemanları Teklif Fiyatı Tahmininde Yapay Sinir Ağları (YSA) Kullanımı, 2. Proje ve Yapım Yönetimi Kongresi, İzmir.

17. Bisen, Ö., Dikmen, S.Ü., 2012. Üstyap1 Projelerinin Maliyet Tahmin Çalışmalarında Belirsizliklerin Yapay Zeka Teknikleriyle Analizi, e-Journal of New World Sciences Academy, 7(2), 394-403.

18. Altun, M., Akçamete, A., 2014. Yapay Arı Kolonisi Algoritmasının Zaman-Maliyet Ödünleşim Problemlerine Uygulanması, 3. Proje ve Yapım Yönetimi Kongresi, Antalya.

19. Andaç, M.S., Oral, E.L., 2014. Yapım İşlerinde Çalışan Verimliliğinin Yapay Arı Kolonisi Algoritması Kullanılarak Tahmini, 3. Proje ve Yapım Yönetimi Kongresi, Antalya.

20. Bayram, S., Öcal, M.E., Laptalı Oral, E., Atiş, C.D., 2016. Comparison of Multi Layer Perceptron (MLP) and Radial Basis Function (RBF) for Construction Cost Estimation: The Case of Turkey, Journal of Civil Engineering and Management, 22, 480-490.

21. Bayram, S., Al-Jibouri, S., 2016. Efficacy of Estimation Methods in Forecasting Building Projects' Costs, Journal of Construction Engineering and Management-ASCE, 142(11).

22. Koğ, F., Yaman, H., 2016. E-İhale Süreçlerinin Yapay Zekâ ve Benzetim Yöntemleri ile Optimizasyonu, 4. Proje ve Yapım Yönetimi Kongresi, Eskişehir.

23. Dobrucal1, E., Demir, İ.H., 2017. Yap1 Yaklaşık Maliyet Hesaplarında Yapay Zeka Tekniğinin Uygulanabilirliğinin Bir Vaka Çalışması Üzerinde İncelenmesi, 5. Uluslararası Mühendislik ve Bilim Alanında Yenilikçi Teknolojiler Sempozyumu (ISITES2017), 489-496 Bakü, Azerbaycan.

24. Keleş, M.K., Keleş, A.E., 2017. Veri Madenciliği Uygulamalarının ve Sezgisel Optimizasyon Algoritmalarının Yapım Yönetimindeki Yeri, Çukurova Üniversitesi Mühendislik-Mimarlık Fakültesi Dergisi, 32(1), 235-242.

25. Mitchell, M., 1998. An Introduction to Genetic Algorithms, Massachusetts Institute of Technology, Cambridge, MA, USA, ISBN: 9780262133166
26. Goldberg, D.E., 1989. Genetic Algorithms in Search, Optimization and Machine Learning, Addison-Wesley, ISBN: 978-0201157673.

27. John, G.H., Langley, P., 1995. Estimating Continuous Distributions in Bayesian Classifiers, $11^{\text {th }}$ Conference on Uncertainty in Artificial Intelligence, San Mateo, 338-345.

28. Witten, I.H., Frank, E., 2005. Data MiningPractical Machine Learning Tools and Techniques $\left(2^{\text {nd }}\right.$ Ed.), Morgan Kaufmann, ISBN: 978-0120884070.

29. Platt, J., 1998. Fast Training of Support Vector Machines Using Sequential Minimal Optimization, Advances in Kernel MethodsSupport Vector Learning, MIT Press, Cambridge, MA, 185-208.

30. Kohavi, R., 1995. The Power of Decision Tables, $8^{\text {th }}$ European Conference on Machine Learning, Springer, 174-189.

31. Quinlan, R., 1993. C4.5: Programs for Machine Learning, Morgan Kaufmann Publishers, San Mateo, CA.

32. Brijain, M., Patel, R., Kushik, M., Rana, K., 2014. A Survey on Decision Tree Algorithm for Classification, International Journal of Engineering Development and Research, 2(1), $1-5$. 